Article

\title{
Analysis of Guidelines and Identification of Characteristics Influencing the Deconstruction Potential of Buildings
}

\author{
Roberta Carvalho Machado ${ }^{1, *}$, Henor Artur de Souza ${ }^{1}$ and Gustavo de Souza Veríssimo ${ }^{2}$ (D) \\ 1 Civil Engineering Postgraduate Program-Steel Construction, Federal University of Ouro Preto-UFOP, \\ Ouro Preto, Minas Gerais 35400-000, Brazil; henorster@gmail.com \\ 2 Civil Engineering Postgraduate Program, Federal University of Viçosa (UFV), \\ Viçosa, Minas Gerais 36570-900, Brazil; gustavo@ufv.br \\ * Correspondence: robertamachadosst@gmail.com; Tel.: +55-31-98867-8038
}

Received: 18 June 2018; Accepted: 23 July 2018; Published: 25 July 2018

check for updates

\begin{abstract}
Growing concerns regarding environmental preservation and the fact that the construction industry is one of the sectors with the highest rates of resource consumption and waste generation, have encouraged the adoption of deconstruction as an alternative to the demolition of buildings at the end of their lifecycle. However, the choice of strategies to enable deconstruction requires an in-depth knowledge of how the building's characteristics, combined with the procedures adopted in the deconstruction process, will affect the reutilization of materials and components. In this paper, characteristics relating to design for deconstruction (DfD) are identified and the influence of each characteristic on the viability of a deconstruction is analysed. A literature review is conducted to assess the guideline of DfD and to identify relevant characteristics. These characteristics are then divided into the following categories: direct influence enabling deconstruction; influence on the ease of the process; and, influence on prolonging a building's lifecycle. A number of questions are suggested for analysing each characteristic, and these can be employed in the development of a methodology for evaluating a building's deconstruction potential. The identification of characteristics involved in the deconstruction guidelines may assist in the optimization of projects and the planning of deconstruction processes.
\end{abstract}

Keywords: deconstruction; reutilization; design for deconstruction (DfD); characteristics influencing deconstruction

\section{Introduction}

The construction industry is one of the most important economic sectors in most countries; it involves numerous processes and it is responsible for the generation of many products and jobs, both directly and indirectly. However, it is also noted worldwide for the considerable environmental impacts that it causes at all stages of its production chain.

The negative environmental effects of the construction industry began to be recognized in the 1990s [1]. According to Agopyan and John [2], the production chain that is associated with civil construction is being forced, at an international level, to undergo cultural, technological, and behavioural changes in order to meet the claims of an increasingly enlightened and demanding society with respect to environmental preservation.

According to Saghafi and Hosseini Teshnizi [3], the most efficient method to reduce the environmental impacts of the building industry is the strategy in which the whole building is repaired and reused. When the whole structure is reused or the building components are assumed to be fully reused, without changing their form or nature, significant reductions in environmental 
impacts are made because this end-of-life scenario probably consumes a smaller amount of energy. Such reuse scenarios are preferable than when the dismantled material is used as raw material in a new production process.

Owing to the shift in the population's environmental concerns and to the high rates of waste generation that is caused by the demolition of buildings at the end of their lifecycle, the concept of deconstruction has emerged as an alternative to traditional demolition and to the depositing of waste in landfills. The deconstruction of a building, also known as disassembly or selective demolition, is a process through which a building is carefully disassembled with the aim of recovering and reutilizing construction materials [4].

However, not all buildings have the potential for deconstruction or for the reutilization of their construction materials. The possibility of recovering building materials depends on how a building was designed and constructed, and on the deconstruction technique that is applied at the end of the building's lifecycle [5]. Although deconstruction techniques offer several advantages over demolition, they are complex, since they resemble a construction process to a much greater extent than traditional demolition [6].

Information on deconstruction projects and on the deconstruction process is still limited, since the number of deconstructed buildings is currently very small. This has encouraged researchers to develop guidelines to enable and facilitate the deconstruction of buildings at the end of their lifecycle. According to Kibert [7], the concept of "design for deconstruction" (DfD), which is also known as "design for disassembly", appeared in the beginning of the 1990s, and it aims to close the cycle of construction materials by including principles that allow for their deconstruction. Although the concept is spreading, there are still few buildings that have been designed under DfD guidelines [8].

Several lists of DfD guidelines are provided in research papers [9-14], resulting in a comprehensive set of principles that provide a basis for the modern DfD process. However, these lists do not point out the characteristics that are related to these guidelines and how they ought to be considered in a deconstruction viability analysis. Which conditions need to be fulfilled in order to analyse a building's deconstruction potential? Which characteristics facilitate deconstruction, but do not prevent the process if not fulfilled? Which conditions must be adopted, at least minimally, in order to ensure the viability of the process?

In this paper, an analysis is presented of DfD guidelines for the identification of characteristics that are influencing the reutilization process of components from a building at the end of its lifecycle, in order to establish parameters that may help the development of a methodology for evaluating a building's deconstruction potential.

A discussion of each characteristic involved in deconstruction and the recognition of how each characteristic influences the deconstruction potential can aid professionals working in civil construction and building owners in terms of investigating a building's viability, since it can provide decision makers with a reference for an initial qualitative analysis prior to a more in-depth, quantitative, laborious analysis. The identification of characteristics and possible questions for analysing the consequences for deconstruction can also serve as a basis for developing methodologies for analysing the deconstruction potential of a building.

\section{Terms and Definitions}

According to Crowther $[9,15]$, there are four end-of-life scenarios (also recognizable as recycling strategies) to building materials and components or to the whole building:

(1) building reuse or relocation, which consist in a relocation of the whole building;

(2) component reuse or relocation in a new building;

(3) material reuse in the manufacture of new building components; and,

(4) materials recycling (down cycling) into new building materials, which is the recycling of waste where the recycled material is of lower quality and functionality than the original material. 
Other authors assume different definitions $[3,14,16]$.

The following definitions are assumed in this research.

Natural resources are extracted and transformed into materials. Materials are seen as the basic parts of buildings. The materials could be connected to form sub-assembly: "component" [9]. Construction components can be connected to form higher-level assembly: system [16,17].

The terms "Building materials" or "Construction materials" are used as generic terms to refer to materials, components and any kind of construction products.

The term "Reuse" is used for the action or practice of using something again, whether for its original purpose (conventional reuse) or to fulfil a different function. Reuse might imply upgrading or some renovation.

The term "Recycle" is used when the construction material is used as raw material, to substitute natural resources, and make a new building material or other product.

\section{Literature Review}

Although there are already historical examples of buildings that are designed for deconstruction, such as the Ise Grand Shrine in Japan, which has been disassembled and rebuilt every 20 years for the last 1300 years [18], and more recent examples, such as the Office Building XX, which was designed by architect Jouke Post and built in the Netherlands in 1999 [19], both DfD and the deconstruction process itself are new research fields involving the construction industry, in which a tendency towards the reutilization of building materials is a fairly recent development.

As a concept, DfD has already been consolidated through the practice of assembling and disassembling lines in the transformation industry [14]. However, the unique characteristics of buildings as products have raised specific problems in the context of recovering construction materials and minimizing waste, since they possess particular characteristics that can hinder the applicability of DfD, for example, the size and complexity of a construction, the development of unique products (buildings are heterogeneous), itinerant construction site, duration period of products, and so on $[7,18,20]$.

In 1999, the International Council for Research and Innovation in Building Construction (CIB) formed Task Group 39 (TG39), whose aim was to produce a comprehensive analysis and report on deconstruction of buildings worldwide and reuse programs, in order to make deconstruction and reuse of building materials a viable option, as an alternative to demolition and landfill [14]. Several annual meetings were conducted during the four years that followed, each resulting in a single publication (CIB 252 [21], CIB 266 [22], CIB 272 [23], and CIB 287 [24]) containing articles of researchers from several countries.

In recent years, progress has been made in the field of building deconstruction, both in terms of research development and in practical terms, with several buildings being deconstructed or designed for this purpose. Several works [9-14] have established guidelines for orienting designers towards incorporating characteristics that can influence both the extension of a building's lifecycle and the development of techniques for the reutilization of construction materials and for the building's future deconstruction.

Tools for analysing buildings with a focus on the reutilization of construction materials have been developed, such as Sakura [25], which can quantify the energy that is embodied and carbon emissions that are spared through the reutilization of structures, and SMARTWaste [26], which provides a mechanism through which waste can be verified and categorized in terms of its origin, type, amount, reuse potential, and cost. Guy and Ohlsen [27] developed a software application based on economic variables (such as local workforce, elimination costs, and the value of recyclable and reusable construction materials) to estimate the costs and efficacy of deconstruction in comparison to the traditional demolition of buildings with wood-framed structures of one or two floors. Studies regarding the economic implications of conventional demolition and deconstruction have also been presented [28]. 
Methods for evaluating the reutilization potential of buildings and the benefits that are derived from recovering construction materials, with a focus on calculating the optimal utilization of the embodied energy of materials in the case where building materials are recovered and reutilized, have also been proposed $[3,14,18]$.

More recent studies of deconstruction have primarily focused on environmental impact analyses undertaken at the end of buildings' lifecycle. Several research subjects have been tackled, such as a detailed project analysis and quantitative surveys of building materials to evaluate and calculate the recyclability index of typical end-of-life building materials [29,30]; a survey of the impact of greenhouse gas emissions (GGE) and energy savings [31]; a comparison of energy savings in the cases of steel reutilization or recycling [32]; estimations of the cost, energy usage, and carbon footprint resulting from four strategies that could be employed at the end of a building's lifecycle [33]; and, estimations of how much new steel is saved in a building by the partial reuse of structural elements coming from deconstruction [34]. All of these evaluations presuppose the existence of detailed project analyses and quantitative surveys of materials/components from pre-existing buildings for evaluating the environmental impacts of deconstruction.

In terms of methodologies for evaluating deconstruction, Akinade et al. [35] propose an evaluation system that is based on DfD principles related to the selection of materials, called BIM-DAS (Building Information Modelling-Deconstructability Assessment System), with the purpose of determining from the project stage whether a building can be deconstructed. Akanbi et al. [36] have also developed a model to estimate the output of recovering structural components from buildings based on BIM (BIM-based Whole-life Performance Estimator, or BWPE), using factors that influence material reuse and recycling, combined with mathematical modelling and the Weibull concept of reliability distribution for manufactured products.

Yeung et al. [37] propose a decision-making framework based on structural analysis, lifecycle analysis, and economic analysis, in order to aid those involved in the initial phases of a deconstruction process in identifying opportunities for the reuse of structural steel. Moynihan and Allwood [38] investigate the behaviour of steel bolts as demountable composite connectors and the possibility of reusing composite beam with bolted connectors by evaluating their resistance.

Experimental studies on demountable shear connectors [39,40] have been carried out. Aninthaneni and Dhakal [41,42] proposed a demountable concrete building system that is suitable for seismic regions.

In Netherlands, several demountable structural systems for building have been implemented, such as an apartment on the Eindhoven University of Technology campus, as a trial module to Industrial, Flexible, and Demountable (IFD) building system [17]. More recent research on demountable structural system in the Netherlands also has been developed by Maheninggalih [43] and Braendstrup [44].

Most studies of deconstruction address the possible environmental and economic benefits of construction material recovery, but few have investigated the principles of DfD for the purpose of elaborating on how a project can be conceived for future disassembly and reutilization, and which conditions must be met, not only in the building project's initial phase, but also in the deconstruction process itself. Although several studies of the principles of DfD in terms of project guidelines already exist [9-14], and despite recent studies addressing the principles of DfD, the focus of these studies has been on the characteristics of building materials [35,36]. However, DfD principles go beyond the selection of construction materials and economical and environmental matters. Not all principles ensuring the possibility of reutilization or recycling contribute to deconstruction [35], since there are important principles involving the methodology and planning of the deconstruction that may directly impact the viability of the procedure.

None of these studies have presented an effective evaluation of each DfD-related guideline and its influence on the viability of deconstructing a building, and none of these evaluation methods use analysis criteria involving matters of process organization, management, and security, which also form 
part of the DfD principles and must be considered and fulfilled when planning a viable deconstruction. Thus, it is important to investigate each individual guideline and to identify all characteristics, so that future methodologies for analysing deconstruction can consider all essential characteristics as evaluation parameter, rather than solely those related to construction materials.

\section{Materials and Methods}

The first step in this work consisted of analysing specific publications from renowned authors and pioneers in the research field, in order to map the main guidelines of DfD. The works that were analysed were:

(1) Thormark [14], cited in recent works [31,35]. The author has a publication in CIB 266 [22] and was a reviewer of CIB 272 [23] and CIB 287 [24];

(2) Crowther [9], cited in recent works [35,36] and referenced by Barth and Vefago [30]. The same DfD guidelines are indicated in more recent works $[15,45]$. This author has publications in CIB 252 [21], CBI 266 [22], CIB 272 [23] and was a reviewer for CIB 272 [23] and 287 [24];

(3) Morgan and Stevenson [11], cited in a recent work [25]; and,

(4) Webster and Costello [12], also cited in recent works [35,38].

Following this analysis, DfD guidelines were identified, synthesized (so that their main concept was obtained), and classified by subject, based on common characteristics.

When considering that a construction is the result of the execution of a set of processes on elements or systems, the concepts of elements, systems, and processes were adopted as references to propose a classification according to which the guidelines were grouped by common characteristics. At the end of this process, seven categories were identified and proposed to organize DfD guidelines.

Table 1 presents 37 guidelines, separated by category, with references to the works that cite them. The aim of the referred Table 1 was to elaborate a classification that was neither too extensive nor excessively generic, which covered all issues that are related to deconstruction, as discussed in the cited literature in order to facilitate its use.

Table 1. Design for deconstruction (DfD) guidelines classified by subject and their respective references.

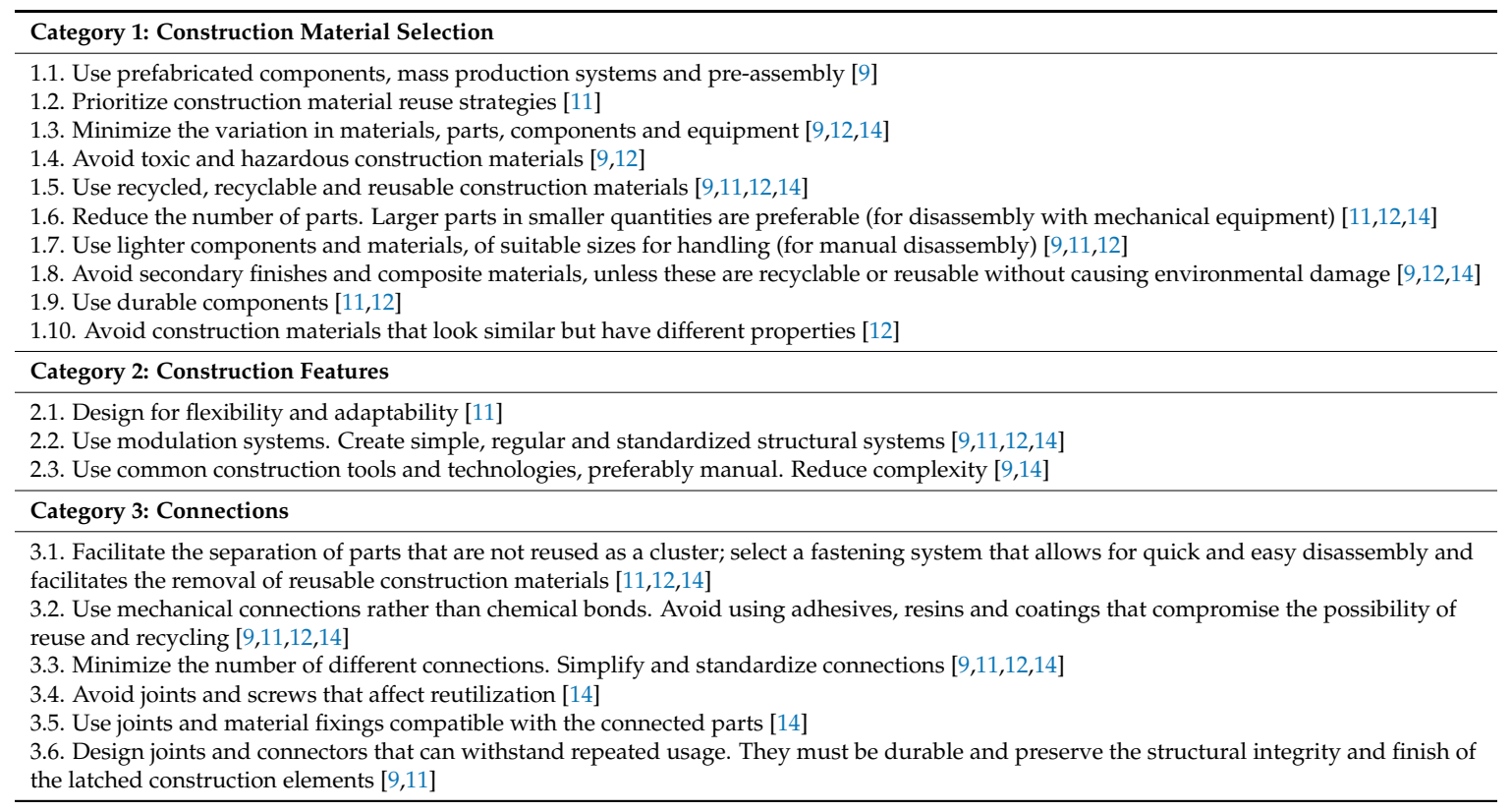


Table 1. Cont.

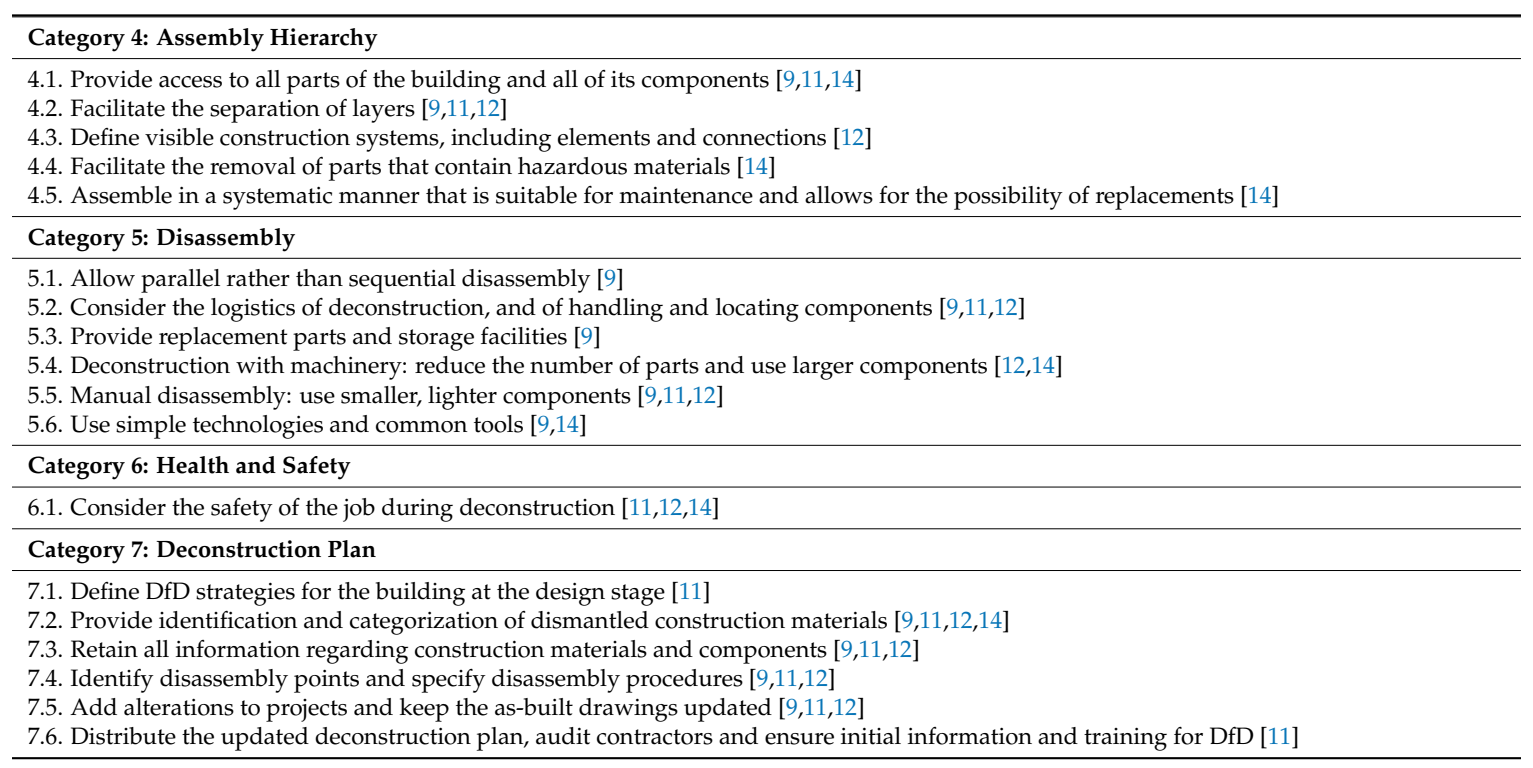

The deconstruction guidelines were analysed to identify their characteristics based on the propositions of Crowther [9,15], Van Gassel [17], Van Herwijnen [46], and Akinade [35]. Three types of influences that the characteristics of the guidelines can exert on deconstruction have been proposed, as follows:

(1) direct influence: characteristics deemed essential to the viability of future deconstruction, which must be considered under ideal or acceptable conditions;

(2) influence on the ease of the process: characteristics that contribute to the facilitation of deconstruction, but are not determinants in enabling the process; and,

(3) influence on prolonging lifecycle: characteristics that favour and facilitate maintenance and substitution of construction materials, and that promote the adaptation of the current building for new uses. In other words, characteristics that enable the deconstruction of parts in order to prolong a building's lifecycle.

Following this, questions for analysing each characteristic when evaluating the deconstruction potential were suggested.

\section{Identification of Characteristics Influencing Deconstruction Potential}

From a qualitative analysis of the guidelines listed in Table 1, it was identified which characteristics could be evaluated to determine their influence on the feasibility of deconstruction. Every characteristic identified were considered equally important without distinction. In Table 2, these characteristics are related to the guidelines listed in Table 1.

A careful analysis of the guidelines and possible activities that are involved in the deconstruction process (accesses, types of equipment, manoeuvrability) allowed for the evaluation of the kind of influence of each characteristic on the feasibility of the deconstruction.

The identified characteristics were evaluated in terms of the possibility of deconstruction and the reutilization of components from a building whose lifecycle has reached its end, in the case where all possible uses and adaptations for the building have already been considered and there are no more possibilities for its utilization as a whole. The types of influence were separated into three categories: (a) direct influence; (b) influence on the ease of the process; and, (c) influence in terms of prolonging the lifecycle. 
Table 2. DfD reference guidelines (from Table 1) and characteristics to be evaluated.

\begin{tabular}{ll}
\hline \multicolumn{1}{c}{ Guideline Numbers (Table 1 ) } & \multicolumn{1}{c}{ Characteristics for Evaluation } \\
\hline $1.1 ; 1.3 ; 1.10 ; 2.2 ; 5.3$ & Construction material standardization; Components prefabrication \\
2.2 & Modulation \\
$1.4 ; 4.4$ & Material toxicity and r hazardousness \\
$1.2 ; 1.5$ & Possibility of reutilizing building materials \\
1.9 & Expected durability of building materials \\
$2.1,4.5$ & Built environment flexibility and adaptability \\
3.1 & Ease of removing connections: connection removal time and accessibility \\
$3.2 ; 3.4 ; 3.6$ & Expected durability of connections \\
$3.2 ; 3.4$ & Damage to connections during the process \\
3.3 & Connection standardization and simplification \\
3.3 & Number of connections \\
$3.2,3.5 ; 3.6$ & Damage to connected parts during deconstruction \\
$4.1 ; 4.3$ & Connection accessibility; Component accessibility \\
$1.8,4.2 ; 4.4$ & Separation of building materials \\
$4.5 ; 5.1$ & Assembly/disassembly type \\
$1.6 ; 1.7 ; 5.4 ; 5.5$ & Disassembly method (manual or mechanical) \\
$4.3 ; 5.2 ; 7.4 ; 7.6$ & Disassembly procedure \\
$5.2 ; 5.3$ & Facilities for the correct storage of construction materials \\
5.2 & Space for equipment and manoeuvring \\
$2.3,5.6$ & Technology, machinery and tools \\
$6.1 ; 7.6$ & Risk assessment and adoption of security measures \\
7.1 & DfD strategies adopted at the design stage \\
7.2 & Construction material identification system \\
7.3 & Employed construction material information system \\
7.5 & As-built drawings \\
\hline
\end{tabular}

\subsection{Direct Influence Characteristics}

Direct influence characteristics are those related to the viability of deconstruction. The non-fulfilment of minimum parameters can prevent success in deconstruction or construction material reutilization.

\subsubsection{Expected Durability}

Construction materials resulting from deconstruction must have an acceptable remaining lifecycle that is equal to or longer than the desired lifecycle of a new component. According to Agopyan and John [2], products with shorter lifecycles will be replaced earlier, multiplying the environmental impacts from production and generating more waste. Reutilization can cause financial and environmental losses if the construction material needs to be replaced before the end of the new building's lifecycle. Thus, when evaluating the viability of a deconstruction, it is important to consider the expected durability of the construction materials that can be recovered. For instance, if a steel structure that is used for 40 years in a building has a technical durability of 100 years and is then recovered, then assuming that proper maintenance was performed, its expected durability is another 60 years (this will also depend on characteristics, such as the state of conservation of the structure, damage occurring during the deconstruction process, and alteration requirements for the new use).

Brazilian standard ABNT NBR 15575-1:2013 [47], which concerns the performance of residential buildings, defines durability as the capability of a building or a building's systems to perform their functions over time and under certain specified conditions of use and maintenance. This standard defines the project lifespan (PL) as the estimated period of time for which a system is designed to last in order to meet the performance requirements that are established in the standard. Minimal PLs are as follows: 50 years for the structural system, 40 years for external vertical sealing and 20 years for internal sealing, 20 years for the roof and hydro-sanitary installations, and 13 years for internal flooring. 


\subsubsection{Toxicity and Hazardousness}

The avoidance of toxic and hazardous construction materials reduces both the contamination potential of construction materials classified for reutilization and potential risks to the health of workers, which are characteristics that could discourage disassembly [9]. Environmental risks are posed by hazardous materials, such as asbestos and lead, and synthetic, toxic materials used as sealants, pastes, and adhesives, which should be avoided [12] since they require special treatment and the protection of workers. If their usage is inevitable, the removal of these materials must be easy [14] and safe.

\subsubsection{Possibility of Reutilizing Materials}

The deconstruction process is justified when there are building materials that can be reused. Reuse of building materials according to the original purpose, with minor repairs, is the end-of-life scenario that contributes most to reducing the environmental impacts that are caused during a building's lifecycle $[3,14,18,48]$, since they do not involve reprocessing. In most cases, recycling construction materials (when used as raw material to produce new products) does not demand careful dismantle of the building.

\subsubsection{Damage to Connected Parts}

Most chemical connections cause damage to the connected parts when dismantled, and DfD guidelines therefore usually recommend the use of mechanical connections. Guideline 3.2, "Use mechanical connections rather than chemical bonds" (Table 1) must be analysed in terms of the possibility of reusing connections after deconstruction and after possible damage being caused to the connected parts, since there may be chemical connections that do not damage those parts during deconstruction. When the damage that is caused to construction materials in the process is not easy to repair, the viability of deconstruction may be compromised.

\subsubsection{Damage to Connections}

Connections that are not compromised during deconstruction are ideal. In addition to the damage that is suffered by connections during deconstruction, it is important to evaluate whether the connection is truly necessary and whether it could be easily repaired or replaced, which will ensure reuse without compromising the viability of deconstruction. If this is not the case, damage to the connection will compromise the possibility of reuse.

\subsubsection{Separation of Construction Materials}

Guideline 4.2 (Table 1) "Facilitate the separation of layers" relates to layer theory, as devised by Brand [49]. Layer theory offers a useful conceptual structure for dividing a building into layers according to the different lifecycles of different elements; it recognizes that a construction should follow an assembly hierarchy in a manner that facilitates the replacement of layers with shorter lifecycles without interfering with other layers, thus increasing the building's lifecycle. Those with faster replacement cycles must be located closer to the surface, so that they are easier to reach and to ensure the possibility of removal without damaging or interfering with more permanent layers [11]. The importance of layer theory as applied to design and construction is particularly reflected in carrying out maintenance on the building, which should avoid the unnecessary demolition of parts. When it comes to deconstructing the building as a whole, this guideline can be interpreted in terms of analysing the ease of separating an element or component that will be reused from the rest.

In the same vein, guideline 1.8 (Table 1) aims to ensure the possibility of reusing construction materials, rather than a prohibition of employing composite construction materials or construction materials with secondary finishes. Thus, the characteristic that is related to this item must be the separation of construction materials when they cannot be reused as a group. 
When a component can be reused without being separated from other materials/components, this characteristic is not significant. There may be cases where separating construction materials is impossible without damaging the construction material and preventing reutilization.

\subsubsection{Space for Equipment and Manoeuvring}

The layout of the deconstruction zone, the shape of the building, and the size and projection of equipment and machinery with hoisted components must be analysed to ensure that the necessary manoeuvres to remove components can be performed, when considering their size, weight, and volume. It is also important to control the built environment of the building and the space around it in order to ensure all necessary access for equipment and manoeuvring. In some cases, access for the equipment necessary to carefully dismantle the building may be impossible; this may impede the process, since it can compromise the integrity of construction materials and the safety of the operation.

\subsubsection{Space for Correct Storage of Construction Materials}

The closer the storage space to where deconstruction or re-sale is taking place, the lower the environmental impact and transportation costs. The location must not affect urban areas and it must be a safe environment. It is necessary to evaluate whether the space and storage method are adequate for the construction materials, or whether damage may be caused, compromising reutilization.

\subsubsection{Risk Assessment and the Adoption of Security Measures}

Reducing, controlling, and, when possible, eliminating the risks that are involved in the dismantling of a building must be a priority in order to preserve the lives of workers and individuals moving around the deconstruction area and to preserve construction material goods, including properties near to the building. The risks of the process must be identified, according to the activities planned, and adequate means of control must be implemented. Moreover, training of the work team must also be carried out.

\subsubsection{Disassembly Procedure}

The guidelines related to this characteristic are related to the planning of the deconstruction process. A basic deconstruction plan must be provided that contains technical procedures and adequate methods to ensure safety during operations. These documents must contain considerations of and recommendations for the deconstruction procedure, and in particular, the order of disassembly, ideal element and component removal techniques, the location of construction materials that will be reutilized, lifting points, an equipment list, the tools and machinery that will be necessary, and a safety plan, among other aspects.

\subsubsection{As-Built Drawings}

The as-built drawings can aid in the identification of parts and the development of disassembly procedures more easily and safely, and especially the order of disassembly, since it provides clarity on the exact nature of any installations or products utilized. If the as-built drawings are non-existent or insufficiently updated, an architectural/structural design update, according to the building, must be conducted, so that disassembly procedures can be efficiently defined.

The Building Information Modelling (BIM) technology, as a process of generating and managing building information during the service life of a building [33] and a rich digital representation [50], can facilitate the integration and management of information throughout the building lifecycle [36]. The usefulness of BIM in architecture and construction engineering has been widely recognized, including research on deconstruction and sustainable building development $[33,35,36,51]$. BIM technology can also facilitate data exchange and integration and it can be used as an information repository to store and deliver as-built information $[50,52]$. It is important to 
keep accurate and complete information stored in a BIM- based building model, so that it serves as a reliable data source towards effective deconstruction.

\subsubsection{DfD Strategies Adopted at the Design Stage}

Disassembling the building will be more viable if DfD strategies are incorporated at the project's design stage. This characteristic involves possible strategies that can be adopted the beginning of construction in order to enable future deconstruction. Even when a building has not been designed for deconstruction, certain basic characteristics that favour deconstruction must be present to enable the process, as well as characteristics that are related to the selection of construction materials and the connections between them.

\subsubsection{Suggested Questions for the Analysis of Characteristics Influencing Directly the Process}

Characteristics that directly influence deconstruction and suggested analysis questions are shown in Table 3.

Table 3. Questions for analysis of the characteristics that have direct influence.

\begin{tabular}{|c|c|c|c|}
\hline Characteristics & Questions for Analysis & Yes & No \\
\hline Expected durability & $\begin{array}{l}\text { Is the expected durability of the component meant for } \\
\text { reutilization longer than or equal to the lifecycle desired } \\
\text { from the new use? }\end{array}$ & + & $\mathrm{x}$ \\
\hline \multirow[b]{2}{*}{ Toxicity and construction material hazardousness } & Are toxic or hazardous construction materials used? & * & + \\
\hline & $\begin{array}{l}\text { If toxic or hazardous construction materials are used, is it } \\
\text { possible to safely and easily remove them? }\end{array}$ & - & $\mathrm{x}$ \\
\hline \multirow{2}{*}{$\begin{array}{l}\text { Possibility of reutilizing (or preferably reusing) } \\
\text { construction materials }\end{array}$} & Can the construction material be reutilized in any way? & + & $\mathrm{x}$ \\
\hline & $\begin{array}{l}\text { Is the deconstruction process necessary to reutilize the } \\
\text { construction material? }\end{array}$ & + & $\mathrm{x}$ \\
\hline \multirow{2}{*}{$\begin{array}{l}\text { Damage caused to connected parts during } \\
\text { construction }\end{array}$} & $\begin{array}{l}\text { Will the connection type cause any kind of damage to } \\
\text { connected parts during deconstruction? }\end{array}$ & * & + \\
\hline & Can any damage arising from deconstruction be repaired? & - & $\mathrm{x}$ \\
\hline \multirow{3}{*}{ Damage to connections during the process } & Will connections be damaged during deconstruction? & * & + \\
\hline & Are connections necessary in the new use? & * & - \\
\hline & $\begin{array}{l}\text { Can connections be repaired or replaced when construction } \\
\text { materials are reutilized? }\end{array}$ & - & $\mathrm{x}$ \\
\hline \multirow{2}{*}{ Construction material separation } & $\begin{array}{l}\text { Is it possible to separate the construction materials meant for } \\
\text { reutilization? }\end{array}$ & + & * \\
\hline & $\begin{array}{l}\text { If separation is impossible, can construction materials be } \\
\text { reutilized as a group without environmental damage? }\end{array}$ & - & $\mathrm{x}$ \\
\hline Space for equipment and manoeuvring & $\begin{array}{l}\text { Is the space around the building sufficient to ensure access } \\
\text { and manoeuvring room for equipment and machinery, } \\
\text { considering the volume of construction materials that will } \\
\text { be removed? }\end{array}$ & + & $\mathrm{x}$ \\
\hline Space for correct storage of construction materials & $\begin{array}{l}\text { Is there an adequate storage space that can ensure that } \\
\text { stored construction materials will not deteriorate? }\end{array}$ & + & $\mathrm{x}$ \\
\hline Risk assessment and adoption of security measures & $\begin{array}{l}\text { Can risks present in the deconstruction process be } \\
\text { eliminated or controlled, allowing procedures to be carried } \\
\text { out safely? }\end{array}$ & + & $\mathrm{x}$ \\
\hline \multirow[t]{2}{*}{ Disassembly procedure } & $\begin{array}{l}\text { Is there a deconstruction procedure with a disassembly } \\
\text { order; an ideal technique for removing components and } \\
\text { elements; locations of construction materials to be removed; } \\
\text { lifting points; and a list of equipment, tools and machinery } \\
\text { necessary and the safety plan? }\end{array}$ & + & $\mathrm{x}$ \\
\hline & $\begin{array}{l}\text { Have deconstruction procedures, including the safety plan, } \\
\text { been passed on to those involved in the process, raising the } \\
\text { team's awareness? }\end{array}$ & + & $\mathrm{x}$ \\
\hline \multirow{2}{*}{ As-built drawings } & $\begin{array}{l}\text { Are there an updated as-built drawings of the building that } \\
\text { will be deconstructed? }\end{array}$ & + & * \\
\hline & $\begin{array}{l}\text { Is there an architectural/structural design update, according } \\
\text { to the building? }\end{array}$ & - & $\mathrm{x}$ \\
\hline \multirow{2}{*}{ DfD strategies adopted at the design stage } & $\begin{array}{l}\text { The characteristics listed in this Table } 3 \text { are considered under } \\
\text { ideal or acceptable conditions? }\end{array}$ & + & * \\
\hline & $\begin{array}{l}\text { Are there actions which could be taken after construction to } \\
\text { change the characteristics' condition and make the } \\
\text { deconstruction viable? }\end{array}$ & - & $\mathrm{x}$ \\
\hline
\end{tabular}

Legend: + Ideal condition-positive aspect; - Acceptable condition-negative aspect; $x$ Condition that can impede deconstruction; * The analysis of deconstruction viability depends on the next quesiton. 
In Table 3, the ideal condition, symbolized by the positive sign, means the best condition of each characteristic, and represents its positive aspect in the deconstruction process. The acceptable condition, which is symbolized by the negative sign, means that the characteristic's condition is not ideal, but it does not influence the viability of future deconstruction, although it represents a negative aspect in the deconstruction process. The condition that can impede deconstruction is represented by the " $x$ " sign. When the analysis of deconstruction viability depends on the next question, the asterisk sign is used.

\subsection{Characteristics Influencing the Ease of the Process}

Characteristics influencing the ease of the deconstruction process are related to its efficiency, to economics, and to the length of time that the procedures will take. Although they facilitate the deconstruction process and the reutilization of components, if these characteristics are not present, deconstruction will not become impossible.

\subsubsection{Standardization and Pre-Fabrication}

Some of the guidelines directly relate to the selection of construction materials, and recommend the use of standardized and pre-fabricated components. These characteristics facilitate quality control and the replacement of components, potentially extending the building's lifecycle. During deconstruction, the characteristics of these construction components reduce the amount of work and the procedures that are required in the process, thus accelerating its completion, facilitating the sorting of removed construction materials, saving resources, and reducing transportation to different recycling/reuse sites. Moreover, the selection of similar components and materials facilitate the reutilization.

\subsubsection{Standardizing and Simplifying Connections}

In the same way that standardized components facilitate deconstruction, the standardization and simplification of connections can make disassembly even faster, reducing the need for different tools and facilitating the replacement of any connections that are damaged in the process.

\subsubsection{Modulation}

Modular coordination facilitates compatibility with other systems and elements (both dimensionally and functionally), thus facilitating the reuse of construction materials.

\subsubsection{Technology, Machinery and Tools}

The use of common construction technology and common tools (preferably manual tools) simplifies the deconstruction process and can lower costs. It is necessary to evaluate the availability of workforce, technologies, and tools that are required for deconstructing. Special technologies, due to their higher levels of complexity, can hamper the process in locations where few skilled workers are available and can raise costs.

\subsubsection{Accessibility to Parts and Connections}

Access to elements for repair and removal can be considered in three different ways [11]: (i) sequential access, which is related to layer theory, implies that access to an element is ill-conceived if the element is positioned in front of another that has a higher chance of requiring removal for maintenance or replacement. Sequential access is important in evaluating maintenance and construction during the building's lifecycle, and it is less relevant when the building is deconstructed as a whole; (ii) physical access, i.e., the possibility of reaching a component and safely removing it completely (in general, the larger the component or construction element, the larger the space necessary for its deconstruction and removal); and, (iii) access to connections, since it is possible that connection 
points between components are hidden by obstacles or their location may be hard to reach, requiring temporary means of access, such as ladders or scaffoldings.

\subsubsection{Number of Connections}

The number of connections influences the deconstruction time, since, in general, the fewer connections involved, the quicker the separation process will be. However, depending on its type, a single connection can be harder to remove than several connections of easily removable types. This characteristic is therefore relative.

\subsubsection{Ease of Removal of Connections}

This guideline is directly related to the ease of disassembly, which depends on the time that is required to remove a fixing, the tools and technologies that are involved, and the accessibility of the disassembly points (the latter two aspects are evaluated based on separate characteristics). Depending on the type of fixing used, the deconstruction process can be made faster and costs minimized.

\subsubsection{Expected Durability of Connections}

The guidelines for this aspect are related to the possibility of reutilization, and can be divided into the following characteristics for analysis: the "expected durability of connections" and the "damage to connections during the process". For chemical connections, such as welds, durability ends when they are broken as a result of the disassembly process, since when welded elements are reused, these connections will have to be remade. Connections that involve an accessory or fitted element can be considered durable if reutilized, and are therefore preferable. Even if the connection used has low durability, the possibility of repair or replacement must be considered (see Section 4.1.5).

\subsubsection{Disassembly Type}

Parallel disassembly is possible when a building's sections can be disassembled independently and simultaneously, and their components can be removed without affecting other components, creating an agile process and lowering the risks of instability.

In sequential assembly and disassembly, each element is fixed in place by a newly-assembled element, creating a linear dependency [13]. The assembly type and structural characteristics of a building often define how it needs to be disassembled.

\subsubsection{Disassembly Method}

Guidelines 1.6 and 1.7 (Table 1) refer to the selection of components, and relate to their size and whether the type of disassembly is manual or mechanical. If components are disassembled mechanically, then they should be larger and fewer; if they are manually disassembled, they should be lighter, with sizes that allow for these components to be adequately handled. Manual disassembly is often recommended, since it is a simpler method, does not require large machinery and it does not demand an elaborate logistics plan. These guidelines seem contradictory since there is no single ideal disassembly type for all components; these may vary in terms of dimensions, weight, quantity, and other relevant specificities. This is also the case with items 5.4 and 5.5 (Table 1), which deal with the same subject, but that are focused on the type of disassembly.

These guidelines can be analysed in terms of the form in which disassembly can be conducted and the difficulty of the process. Disassembly while using equipment is often more expensive, may involve greater risk, and require a skilled workforce. However, it can make the process faster when the building consists of larger pieces in fewer quantities. 


\subsubsection{Construction Material Identification System}

Any efficient means of identification may be used for the identification of components, whether by tagging or another more definitive method. A marking system and the definitive identification of parts can aid in this process. The identification of disassembled parts is important for their organization during deconstruction, since it aids in recognizing and quantifying parts by type, size, weight, and function, in addition to facilitating their separation and provision for reuse.

\subsubsection{Information System for Construction Materials Used}

It is recommended to organize a file, starting from the phase when the selection of construction materials and suppliers are defined, in the format of a memorial, listing the materials and components used, their specifications, and all of the basic information that may be useful in the deconstruction process, such as: the lifecycle, reutilization potential, manufacture date, resistance of the construction material, special handling instructions, preservation and maintenance methods, warranties, manufacturer details, recycling collection points, and so on. This information may make a valuable contribution to decisions made during the process of evaluating the deconstruction potential.

\subsubsection{Suggested Questions for the Analysis of Characteristics Influencing the Ease of the Process}

Characteristics that influence the ease of deconstruction and suggested questions for analysis are presented in Table 4.

Table 4. Questions for analysis of the characteristics that influence the ease of the process.

\begin{tabular}{|c|c|c|c|c|}
\hline Characteristics & Questions for Analysis & Yes & No & $\begin{array}{c}\text { Possible Consequences of the Characteristics' } \\
\text { Negative Impact }\end{array}$ \\
\hline $\begin{array}{l}\text { Standardization, } \\
\text { components pre-fabrication }\end{array}$ & $\begin{array}{l}\text { Are construction materials standardized } \\
\text { and pre-fabricated? }\end{array}$ & + & - & \multirow{2}{*}{$\begin{array}{l}\text { Difficulty in organizing and separating construction } \\
\text { materials; } \\
\text { Wider range of procedures and tools necessary for } \\
\text { deconstruction; } \\
\text { Increase in the amount of work and process duration; } \\
\text { Increase in cost; } \\
\text { Difficulty in reuse and replacement }\end{array}$} \\
\hline $\begin{array}{l}\text { Standardization and } \\
\text { simplification of connections }\end{array}$ & $\begin{array}{l}\text { Are connections simplified and } \\
\text { standardized? }\end{array}$ & + & - & \\
\hline Modulation & $\begin{array}{l}\text { Are the building and its components } \\
\text { modulated? }\end{array}$ & + & - & Difficulty in reuse \\
\hline \multirow{2}{*}{$\begin{array}{l}\text { Technology, machinery } \\
\text { and tools }\end{array}$} & $\begin{array}{l}\text { Is the use of basic technology and tools } \\
\text { sufficient for deconstruction? }\end{array}$ & + & - & \multirow[t]{2}{*}{$\begin{array}{l}\text { Difficulties in hiring skilled workers; the use of specialist } \\
\text { technologies can increase costs and delay activities }\end{array}$} \\
\hline & $\begin{array}{l}\text { Is an adequate workforce available for } \\
\text { deconstruction activities? }\end{array}$ & + & - & \\
\hline \multirow{2}{*}{$\begin{array}{l}\text { Accessibility of parts } \\
\text { and connections }\end{array}$} & $\begin{array}{l}\text { Are there difficulties in accessing } \\
\text { connections and components? }\end{array}$ & - & + & \multirow[t]{2}{*}{$\begin{array}{l}\text { Access difficulties can cause delays and damage to } \\
\text { construction materials, and can increase costs and risks }\end{array}$} \\
\hline & $\begin{array}{l}\text { Are temporary means of access necessary, } \\
\text { such as ladders or scaffolding? }\end{array}$ & - & + & \\
\hline Number of connections & $\begin{array}{l}\text { Is the number of connections between } \\
\text { components excessive? }\end{array}$ & - & + & Increase in time required for deconstruction \\
\hline Ease of connection removal & $\begin{array}{l}\text { Does the removal of each fixing take a } \\
\text { long time? }\end{array}$ & - & + & May increase deconstruction time and costs \\
\hline \multirow{2}{*}{$\begin{array}{l}\text { Expected durability } \\
\text { of connections }\end{array}$} & $\begin{array}{l}\text { Can the connections be reused after } \\
\text { deconstruction? }\end{array}$ & + & - & \multirow[b]{2}{*}{ May increase costs } \\
\hline & $\begin{array}{l}\text { Is the expected durability of the } \\
\text { connection intended for reuse larger than } \\
\text { or equal to that of the new use? }\end{array}$ & + & - & \\
\hline Disassembly type & Is parallel disassembly possible? & + & - & $\begin{array}{l}\text { Sequential disassembly: Higher instability risks, longer } \\
\text { process }\end{array}$ \\
\hline Disassembly method & $\begin{array}{l}\text { Is manual disassembly possible, and is it } \\
\text { adequate for the construction materials to } \\
\text { be removed? }\end{array}$ & + & - & $\begin{array}{l}\text { Mechanical disassembly: Can increase risks and the cost } \\
\text { of procedures }\end{array}$ \\
\hline $\begin{array}{l}\text { Construction material } \\
\text { identification system }\end{array}$ & $\begin{array}{l}\text { Is there an efficient system for identifying } \\
\text { construction materials? }\end{array}$ & + & - & $\begin{array}{l}\text { Difficult organization and identification of construction } \\
\text { materials }\end{array}$ \\
\hline $\begin{array}{l}\text { Information system used for } \\
\text { construction materials }\end{array}$ & $\begin{array}{l}\text { Is there an efficient information system } \\
\text { for construction materials? }\end{array}$ & + & - & $\begin{array}{l}\text { Difficult organization and reutilization of construction } \\
\text { materials }\end{array}$ \\
\hline
\end{tabular}

Legend: + Positive impact of the characteristic; - Negative impact of the characteristic. 


\subsection{Characteristics Influencing Lifecycle Extension}

Some DfD guidelines aim to prolong the lifecycle of a building; that is to say, they favour and facilitate maintenance and the replacement or replenishment of parts and construction materials, and they promote the adaptation of the existing building for new uses rather than deconstructing it entirely. It is understood that these measures avoid the need for a building to be demolished, allowing for partial deconstruction of only that part that needs to be modified in order for the building to remain useful.

Certain characteristics may influence lifecycle extension and simultaneously influence the ease of total deconstruction, since they indirectly facilitate the replacement of components. These include "standardization"; "pre-fabrication"; "modulation"; "standardization of connections"; "accessibility of connections" and "accessibility to parts" (sequential access, see Section 4.2.5); "disassembly type"; and, "space for equipment and manoeuvring". The guideline in item 4.2 of Table 1, "facilitate the separation of layers", is particularly focused on the maintenance of the building, thus avoiding the needless demolition of parts. Thus, the characteristic "separation of construction materials" may also influence the extension of the building's lifecycle, since it facilitates the separation of construction materials that can be replaced, as long as assembly follows the hierarchy that is suggested by Brand [49] (see Section 4.1.6).

In addition to the characteristics that are cited above, the characteristic "Built environment flexibility and adaptability" may allow for alterations in the building layout, when deconstruction is not necessary or favours small deconstructions that allow the adaptation of a building for new uses. Guidelines 2.1 and 4.5 (Table 1) are interpreted in the sense of the need for a flexible built environment in order to prolong the building's lifecycle, favouring maintenance, component replacement, and adaptation. Since these are indirectly connected to other characteristics that deal with the ease of replacing components, they also positively influence deconstruction.

Suggested Questions for the Analysis of Characteristics Influencing Lifecycle Extension

Characteristics influencing the length of the building's lifecycle and suggested questions for analysis are presented in Table 5.

Table 5. Questions for analysis of the characteristics that influence lifecycle extension.

\begin{tabular}{|c|c|c|c|}
\hline Characteristics & Questions for Analysis & Yes & No \\
\hline \multirow[b]{2}{*}{$\begin{array}{l}\text { Standardization/pre-fabrication of } \\
\text { construction materials }\end{array}$} & Are construction materials standardized and pre-fabricated? & + & - \\
\hline & $\begin{array}{l}\text { Are there stored or available construction materials that can be used as } \\
\text { replacements in the building? }\end{array}$ & + & - \\
\hline \multirow[b]{2}{*}{ Standardization of connections } & Are connections standardized? & + & - \\
\hline & $\begin{array}{l}\text { Are there stored or available connections that can be used as replacements in the } \\
\text { building? }\end{array}$ & + & - \\
\hline Modulation & Are the construction and its components modulated? & + & - \\
\hline \multirow[t]{2}{*}{ Accessibility of parts and connections } & $\begin{array}{l}\text { Are there difficulties in accessing connections and components that need to be } \\
\text { replaced? }\end{array}$ & - & + \\
\hline & Are temporary means of access necessary, such as ladders and scaffolding? & - & + \\
\hline \multirow{2}{*}{$\begin{array}{l}\text { Separation from other } \\
\text { construction materials }\end{array}$} & $\begin{array}{l}\text { Were the parts of the building constructed based on an assembly hierarchy that } \\
\text { allows access to and replacement of layers with shorter lifecycles, without } \\
\text { affecting other layers? }\end{array}$ & + & - \\
\hline & Is it possible to separate construction materials that need to be replaced? & + & - \\
\hline \multirow{2}{*}{ Disassembly type } & $\begin{array}{l}\text { Is the type of assembly/disassembly adequate for maintenance, and does it } \\
\text { allow the possibility of replacement? }\end{array}$ & + & - \\
\hline & $\begin{array}{l}\text { Does the building allow the parallel deconstruction of a part that needs to be } \\
\text { replaced? }\end{array}$ & + & - \\
\hline Space for equipment and manoeuvring & $\begin{array}{l}\text { Is the space around the building sufficient to ensure the access and manoeuvring } \\
\text { of equipment carrying construction materials to be removed, without } \\
\text { compromising the building's integrity? }\end{array}$ & + & - \\
\hline $\begin{array}{l}\text { Built environment flexibility } \\
\text { and adaptability }\end{array}$ & $\begin{array}{l}\text { Does the building allow for the flexibility and adaptability of its built } \\
\text { environment? }\end{array}$ & + & - \\
\hline
\end{tabular}

Legend: + Positive impact of the characteristic; - Negative impact of the characteristic. 
The possible consequences of the characteristic's negative impacts shown in Table 5 are difficulties in prolonging the lifecycle of a building.

\section{Discussion}

According to Akinade et al. [35], the results of comparative case studies for evaluating deconstruction potential, while using an evaluation system based on DfD principles for the selection of construction materials, show that the use of prefabricated building elements and demountable connections are the main characteristics contributing in designing for deconstruction.

We highlight here that demountable connections do not always ensure the possibility of deconstruction, since without good maintenance, mechanical connections may be damaged and cause damage to connected parts during disassembly. Thus, rather than establishing the use of mechanical or demountable connections as an essential aspect, the characteristics "damage to connections"; "damage caused to connected parts during deconstruction"; and, "separation of construction materials" should be considered, since these effectively link the use of connections with the possibility of preserving construction materials during deconstruction, without restricting the use of chemical connections.

The characteristic "prefabricated components" was identified as being influential on the ease of deconstruction.

Although prefabricated components facilitate the logistics of the deconstruction process, components not prefabricated do not prevent the process, although it may become more laborious.

A cast-in-situ component or system does not hinder or complicate the deconstruction process. An example of this is the demountable composite flooring system that was proposed by Braendstrup [44], in which the slab is cast in-situ for the initial use cycle. At the end of initial use cycle, the floor is demounted and reused as prefab elements without the shear connectors. The proposed system preserves the structurally efficient composite flooring system and it is beneficial for the environment because it avoids the transport of precast elements and the use of heavy equipment to assembly of prefabricated elements [44].

Therefore, it is not strictly necessary for the building materials to be prefabricated to enable deconstruction. The possibility of reuse of these building materials will depend on the analysis of other characteristics of Table 3 such as "Possibility of reutilizing", "damage caused to connected parts during deconstruction", and "Construction material separation", which may help in the evaluation of the possibility of reusing construction materials cast in-situ.

Even when the characteristics that influence deconstruction are considered to be positive, reuse can be compromised depending on the need for repair of the building materials. This reveals a loophole in the project guidelines for deconstruction presented in Table 1, since no attention is paid to the maintenance and the state of conservation of construction materials, and to assessing the need for repairs that the construction material will eventually require in order to be reused.

\section{Other Aspects}

By analysing the DfD guidelines, it was observed that there are implicit considerations about the use of durable construction materials. However, it is understood that these aspects must be considered in a more effective way. To that end, three additional characteristics that influence the need for repairing construction materials are suggested, as presented in Table 6.

Through an analysis of the building material that considers these three characteristics, it is possible to evaluate the environmental and economic impacts of the possible repair needs. The more extensive these repair needs, the less advantageous the construction material's recovery; this may make deconstruction infeasible in terms of its environmental impacts, since the repair of the construction material may require more energy, carbon emissions, and natural resources than those required to fabricate a new construction material. The same logic applies in economic terms, in the case where the repair costs are higher than those of acquiring a new product. 
The environmental impacts of deconstruction and the costs of the process have been highlighted in recent studies evaluating deconstruction [29-34,37]. Hence, aspects related to the possible environmental impacts and costs that are involved in the transportation and recuperation of construction materials, and in the deconstruction process itself, must also be observed.

Table 6. Characteristics influencing the need to repair building materials.

\begin{tabular}{ll}
\hline Characteristics & \multicolumn{1}{c}{ Influence } \\
\hline Conservation state & $\begin{array}{l}\text { Refers to the quality of the building material and its condition before deconstruction begins. Directly } \\
\text { connected to its technical durability, wear time, usage conditions and maintenance conducted during the } \\
\text { building's lifecycle. }\end{array}$ \\
\hline \multirow{2}{*}{ Damage during deconstruction } & $\begin{array}{l}\text { Refers to any type of damage the building material may suffer during the deconstruction process. } \\
\text { Damage will be reduced if more deconstruction strategies are used to facilitate the process of separating } \\
\text { and removing materials/components. Using an analysis of the building as a whole, it is possible to } \\
\text { estimate whether the construction component needs to be broken or cut in any way in order to separate it } \\
\text { from another construction material, whether it can be easily disconnected, or whether, for instance, it may } \\
\text { collide with a barrier when hoisted and suffer any damage. }\end{array}$ \\
\hline Repairs for reuse & $\begin{array}{l}\text { Refers to alterations and repairs necessary when the recovered building material is used in a different } \\
\text { way or requires modification or adaptation in order to be reused. In many deconstruction cases, } \\
\text { components are simply disassembled and reassembled elsewhere, without the need for repairs. What } \\
\text { must be evaluated is whether any alteration must be made to the construction material in order to adapt } \\
\text { it for its new use. }\end{array}$ \\
\hline
\end{tabular}

Generally, the deconstruction process and the reutilization of construction materials must generate environmental and economic impacts that are smaller than those of demolishing the building and acquiring new products.

The three characteristics of Table 6 should be analysed together to determine the possible environmental and economic impacts resulting from the need to repair construction materials for reuse, as shown in Table 7.

Table 7. Additional questions for analysis of the characteristics that have direct influence.

\begin{tabular}{c|l|c|c}
\hline \multicolumn{2}{c}{ Characteristics } & \multicolumn{1}{c}{ Questions for Analysis } & \multicolumn{1}{c}{ Yes } \\
\hline Conservation state & $\begin{array}{l}\text { Taking into account the possible environmental impacts: is the } \\
\text { recovery of the building material advantageous, considering } \\
\text { its quality and condition before deconstruction, possible } \\
\text { damages during the deconstruction process and the } \\
\text { alterations and repairs necessary for its reuse? } \\
\text { Are the environmental impacts resulting from the repairs } \\
\text { required to recover the building materials smaller than the } \\
\text { environmental impacts caused by the manufacture of a new } \\
\text { equivalent product? } \\
\text { deconstruction }\end{array}$ & + & \\
\hline Repairs for reuse & $\begin{array}{l}\text { Are the costs involved in the process of recovering building } \\
\text { materials less than the costs of a new equivalent building } \\
\text { material? }\end{array}$ & + \\
\hline
\end{tabular}

Legend: + Ideal condition-positive aspect; - Acceptable condition-negative aspect; $\mathrm{x}$ Condition that can impede deconstruction.

Even if it is subjective, one should practice the ability to estimate costs, including financial investments in deconstruction and building material recovery processes. The comparison of these costs with the value of a new building material with the same function and performance, should also be taken into account, while also considering the possible benefits with the adoption of new construction materials in terms of durability and maintenance need.

Thus, deconstruction must be analysed in terms of the cost of the investments required to promote the reuse of the material resources used in a construction that has reached the end of its lifecycle. Even when the cost is higher, deconstruction can be considered viable depending on the importance of the environmental aspect. 


\section{Conclusions}

In this paper, an analysis of DfD guidelines is presented, the characteristics influencing the deconstruction potential of buildings are identified, and a systematization of the questions for the viability of deconstruction is proposed.

Through this study, it was possible to identify certain characteristics that significantly contribute to the viability of deconstructing a building, and others whose influence is less important. Characteristics that can aid in extending the lifecycle of a building and in partial deconstruction were also identified. For these three categories of characteristics, the positive and negative aspects of how each characteristic influences the deconstruction potential were indicated in order to facilitate analysis.

Through an analysis of the various characteristics that are involved in deconstruction, it was possible to conclude that this process does not need to be an essential consideration for all buildings at the end of their lifecycle, but may be an alternative to demolition when those characteristics that directly influence the process are considered under ideal or acceptable conditions. In addition to these essential characteristics, the economic aspects and possible environmental impacts of recovering and reusing construction materials must be considered when studying the viability of deconstruction.

Knowledge of the characteristics that are essential for deconstruction can aid in a preliminary study of the viability of applying this process to a building at the end of its lifecycle, and it serves as a reference for the development of new building projects intended for future deconstruction.

The categorizations, questions, and relations that are proposed here are intended to provide professionals and those responsible for evaluating the deconstruction potential of a building with tools that can assist in decision making and the elaboration of strategies, both for the original project that is planned for future deconstruction, and in a viability analysis and deconstruction plan for a building at the end of its lifecycle. Methodologies for evaluating the deconstruction potential of a building can be developed based on the questions for analysis suggested here for the characteristics influencing the process.

Author Contributions: R.C.M. and H.A.S. designed the methodology. R.C.M. performed the research. R.C.M. and G.S.V. analysed the data. R.C.M., H.A.S. and G.S.V. wrote the paper.

Funding: This research received no external funding.

Acknowledgments: The authors thank the Fundação Coordenação de Aperfeiçoamento de Pessoal de Nível Superior-CAPES for a scholarship granted to the first author.

Conflicts of Interest: The authors declare no conflict of interest.

\section{References}

1. Sfakianaki, E.; Moutsatsou, K. A decision support tool for the adaptive reuse or demolition and reconstruction of existing buildings. Int. J. Environ. Sustain. Dev. 2015, 14, 1-19. [CrossRef]

2. Agopyan, V.; John, V.M. O Desafio da Sustentabilidade na Construção Civil, 1st ed.; Goldemberg, J., Ed.; Blucher: São Paulo, Brazil, 2011; ISBN 9788521206101.

3. Saghafi, M.D.; Hosseini Teshnizi, Z.S. Recycling value of building materials in building assessment systems. Energy Build. 2011, 43, 3181-3188. [CrossRef]

4. Couto, A.; Couto, J.; Texeira, J. Desconstrução-Uma ferramenta para sustentabilidade da construção. In $6^{\circ}$ NUTAU 2006-Inovações tecnológicas e sustentabilidade, Anais do Seminário Brasileiro da Gestão do Processo de Projecto na Construção de Edifícios, São Paulo, Brazil. 2006. Available online: http: / / repositorium.sdum.uminho.pt/handle/1822/6792?locale=en (accessed on 24 July 2018). (In Portuguese)

5. Couto, J.; Couto, A. Analysis of barriers and the potential for exploration of deconstruction techniques in Portuguese construction sites. Sustainability 2010, 2, 428-442. [CrossRef]

6. Freitas, M.L.G.; Carvalho Filho, A.C.; Brayner, F.M.M. A Desconstrução como Fator de Sustentabilidade na Indústria da Construção Civil. In Proceedings of the ELECS 2009, Anais do III Encontro Latino Americano e V Encontro Nacional sobre Edificações e comunidades Sustentáveis, Recife, Brazil, 28-30 Octuber 2009. (In Portuguese) 
7. Kibert, C.J. Deconstruction: The start of a sustainable materials strategy for the built environment. Ind. Environ. 2003, 26, 84-88.

8. Rios, F.C.; Chong, W.K.; Grau, D. Design for Disassembly and Deconstruction-Challenges and Opportunities. Procedia Eng. 2015, 118, 1296-1304. [CrossRef]

9. Crowther, P. Design for disassembly-Themes and principles. RAIA/BDP Environ. Des. Guid. 2005, 1-7. [CrossRef]

10. Pulaski, M.; Hewitt, C.; Horman, M.; Guy, B. Design for Deconstruction. Mod. Steel Constr. 2004. Available online: https:/ / www.aisc.org/globalassets/modern-steel/archives/2004/06/2004v06_deconstruction.pdf (accessed on 6 November 2015).

11. Morgan, C.; Stevenson, F. Design and Detailing for Deconstruction SEDA Design Guides for Scotland: No. 1; Scottish Ecological Design Association: Scotland, UK, 2005; p. 26.

12. Webster, M.D.; Costello, D.T. Designing Structural Systems for Deconstruction: How to extend a new building's useful life and prevent it from going to waste when the end finally comes. In Proceedings of the Greenbuild Conference, Atlanta, GA, USA, 11-19 November 2005; pp. 1-14.

13. Durmisevic, E. Transformable Building Structures, Design for Disassembly as a Way to Introduce Sustainable Engineering to a Building Design and Construction; Cedris M\& CC: Delft, The Netherlands, 2006; ISBN 9789090203416.

14. Thormark, C. Recycling Potential and Design for Disassembly in Buildings. Ph.D. Thesis, Lund Institute of Technology, Lund University, Lund, Suécia, 2001.

15. Crowther, P. Designing for disassembly. In Technology, Design and Process Innovation in the Built Environment; Newton, P., Hampsom, K., Drogemuller, R., Eds.; Taylor and Francis: Abingdon, UK, 2009; p. 576. ISBN 0203928326.

16. Durmisevic, E.; Brouwer, P.J. Design Aspects of Decomposable Building Structures. In Proceedings of the CIB Publication 272-Task Group 39, Karlsruhe, Germany, 9 April 2002.

17. Van Gassel, F. Experiences with the Design and Production of an Industrial, Flexible and Demountable (IFD) Building System. NIST Spec. Publ. SP 2003, 167-172. [CrossRef]

18. Amoêda, R.P.C. Design for Deconstruction: Emergy Approach to Evaluate Deconstruction Effectiveness. Ph.D. Thesis, Universidade do Minho, Braga, Portugal, 2009.

19. Van Dijk, K.; Boedianto, P.; te Dorsthorst, B.; Kowalczyk, A. State of the art deconstruction in the Netherlands. In CIB Publication 252-Task Group 39; Kibert, C.J., Chini, A.R., Eds.; International Council for Research and Innovation in Building Construction: Watford, UK, 2000; pp. 95-143.

20. Organization for Economic Co-operation and Development (OECD). Environmentally Sustainable Buildings-Challenges and Policies; OECD Publications: Paris, France, 2003.

21. CIB World Building Congress. CIB Publication 252-Task Group 39: Overview of Deconstruction in Selected Countries; Kibert, C.J., Chini, A.R., Eds.; International Council for Research and Innovation in Building Construction: Watford, UK, 2000.

22. CIB World Building Congress. CIB Publication 266-Task Group 39: Deconstruction and Materials Reuse: Technology, Economic, and Policy; Chini, A.R., Ed.; International Council for Research and Innovation in Building Construction: Wellington, New Zealand, 2001.

23. CIB World Building Congress. CIB Publication 272-Task Group 39: Design for Deconstruction and Materials Reuse; Chini, A.R., Schultmann, F., Eds.; International Council for Research and Innovation in Building Construction: Karlsruhe, Germany, 2002.

24. CIB World Building Congress. CIB Publication 287-Task Group 39: Deconstruction and Materials Reuse; Chini, A.R., Ed.; International Council for Research and Innovation in Building Construction: Gainesville, FL, USA, 2003.

25. Densley Tingley, D.; Davison, B. Developing an LCA methodology to account for the environmental benefits of design for deconstruction. Build. Environ. 2012, 57, 387-395. [CrossRef]

26. Hurley, J.; Goodier, C.; Garrod, E.; Grantham, R.; Lennon, T.; Waterman, A.A. Design for Deconstruction-Tools and Practices. In CIB Publication 272-Task Group 39; Chini, A.R., Schultmann, F., Eds.; International Council for Research and Innovation in Building Construction: Karlsruhe, Germany, 2002.

27. Guy, B.; Ohlsen, M. Creating business opportunities through the use of a deconstruction feasibility tool. In CIB Publication 287-Task Group 39; Chini, A.R., Ed.; International Council for Research and Innovation in Building Construction: Gainesville, FL, USA, 2003. 
28. Coelho, A.; De Brito, J. Economic analysis of conventional versus selective demolition-A case study. Resour. Conserv. Recycl. 2011, 55, 382-392. [CrossRef]

29. Vefago, L.H.M.C.; Avellaneda, J. Recycling concepts and the index of recyclability for building materials. Resour. Conserv. Recycl. 2013, 72, 127-135. [CrossRef]

30. Barth, F.; Vefago, L.H.M.C. Desconstrução e potenciais de reciclabilidade nas edificações. Arquitextos 2015, $179,1$.

31. Diyamandoglu, V.; Fortuna, L.M. Deconstruction of wood-framed houses: Material recovery and environmental impact. Resour. Conserv. Recycl. 2015, 100, 21-30. [CrossRef]

32. Ness, D.; Swift, J.; Ranasinghe, D.C.; Xing, K.; Soebarto, V. Smart steel: New paradigms for the reuse of steel enabled by digital tracking and modelling. J. Clean. Prod. 2015, 98, 292-303. [CrossRef]

33. Akbarnezhad, A.; Ong, K.C.G.; Chandra, L.R. Economic and environmental assessment of deconstruction strategies using building information modeling. Autom. Constr. 2014, 37, 131-144. [CrossRef]

34. Pongiglione, M.; Calderini, C. Material savings through structural steel reuse: A case study in Genoa. Resour. Conserv. Recycl. 2014, 86, 87-92. [CrossRef]

35. Akinade, O.O.; Oyedele, L.O.; Bilal, M.; Ajayi, S.O.; Owolabi, H.A.; Alaka, H.A.; Bello, S.A. Waste minimisation through deconstruction: A BIM based Deconstructability Assessment Score (BIM-DAS). Resour. Conserv. Recycl. 2015, 105, 167-176. [CrossRef]

36. Akanbi, L.A.; Oyedele, L.O.; Akinade, O.O.; Ajayi, A.O.; Davila Delgado, M.; Bilal, M.; Bello, S.A. Salvaging building materials in a circular economy: A BIM-based whole-life performance estimator. Resour. Conserv. Recycl. 2018, 129, 175-186. [CrossRef]

37. Yeung, J.; Walbridge, S.; Haas, C. The role of geometric characterization in supporting structural steel reuse decisions. Resour. Conserv. Recycl. 2015, 104, 120-130. [CrossRef]

38. Moynihan, M.C.; Allwood, J.M. Viability and performance of demountable composite connectors. J. Constr. Steel Res. 2014, 99, 47-56. [CrossRef]

39. Rehman, N.; Lam, D.; Dai, X.; Ashour, A.F. Experimental study on demountable shear connectors in composite slabs with profiled decking. J. Constr. Steel Res. 2016, 122, 178-189. [CrossRef]

40. Lam, D.; Dai, X.; Ashour, A.; Rehman, N. Recent research on composite beams with demountable shear connectors. Steel Constr. 2017, 10, 125-134. [CrossRef]

41. Aninthaneni, P.K.; Dhakal, R.P. Demountable Precast Concrete Frame-Building System for Seismic Regions: Conceptual Development. J. Archit. Eng. 2017, 23, 1-10. [CrossRef]

42. Aninthaneni, P.K.; Dhakal, R.P. Demountable Precast RC Frame Building System for Seismic Regions Seismic. In Proceedings of the International Conference on Earthquake Engineering and Seismology (IZIIS-50), Kiel, Germany, 12-16 May 2015.

43. Maheninggalih, G. A Demountable Structural System of Multi-Storey Building Case Study of Car Park Building. Bachelor's Thesis, Delft University of Technology, Delft, The Netherlands, 2017.

44. Braendstrup, C. Conceptual Design of a Demountable, Reusable Composite Flooring System. Bachelor's Thesis, Delft University of Technology, Delft, The Netherlands, 2017.

45. Crowther, P. Re-Valuing Construction Materials and Components through Design for Disassembly. In Proceedings of the Unmaking Waste 2015, Adelaide, South Australia, 22-24 May 2015; pp. 261-269.

46. Van Herwijnen, F. Development of a new adaptable and demountable structural system for utility buildings. In Proceedings of the International Conference Sustainable Building 2000, Rotterdam, The Netherlands, 22-25 October 2000; pp. 22-25.

47. Associação Brasileira de Normas Técnicas. ABNT NBR 15575-1:2013. Residential Buildings_Performance Part 1: General Requirements 2013. p. 71. Available online: http:/ / www.abntcatalogo.com.br/norma.aspx?ID=195568 (accessed on 24 July 2018).

48. Amoêda, R.P.C.; Jalali, S.; Mendonça, P. $9^{a}$ Conferência Nacional do Ambiente. In Proceedings of the 9th Conferência Nacional do Ambiente, Aveiro, Portugal, 18-20 April 2007; Borrego, C., Miranda, A.I., Figueiredo, E., Martins, F., Arroja, L., Fidélis, T., Eds.; pp. 959-966. Available online: http:/ / repositorium. sdum.uminho.pt/handle/1822/7572?locale=en (accessed on 24 July 2018).

49. Brand, S. How Buildings Learn; Vinking Press: London, UK, 1994; ISBN 9780670835157.

50. Gao, T. Constructing a Complete and Accurate As-Built BIM Based on an As-Designed BIM and Progressive Laser Scans. Ph.D. Thesis, Carnegie Mellon University, Pittsburgh, PA, USA, 2014. 
51. Reizgevičius, M.; Ustinovičius, L.; Cibulskieně, D.; Kutut, V.; Nazarko, L. Promoting sustainability through investment in Building Information Modeling (BIM) technologies: A design company perspective. Sustainability 2018, 10, 600. [CrossRef]

52. Lu, Y.; Wu, Z.; Chang, R.; Li, Y. Building Information Modeling (BIM) for green buildings: A critical review and future directions. Autom. Constr. 2017, 83, 134-148. [CrossRef] 